\title{
Integración del dividendo con la renta corporativa
}

\section{Beatriz De la Vega Rengifo}

Abogada por la Pontificia Universidad Católica del Perú. MBA por la Universidad Adolfo lbáñez. Máster en Derecho (LL.M.) por la University of Aberdeen. Docente de la Universidad Nacional Mayor de San Marcos y de la Pontificia

Universidad Católica del Perú.

Geraldine IzaguirRe LóPEZ

Abogada por la Pontificia Universidad Católica del Perú.

SUMARIO:

I. Tratamiento fiscal aplicable a la inversión privada nacional y extranjera.

II. Política fiscal en torno a la gravabilidad de los dividendos.

1. Breve descripción del método de gravabilidad.

1.1. Doble imposición económica e integración impositiva.

1.2. Imposición a nivel de personas jurídicas e incentivo a la reinversión de utilidades.

1.3. Doble imposición económica e imposición cedular.

2. Últimas modificaciones tributarias.

III. Régimen impositivo de los dividendos en el país.

IV. Planeamiento fiscal internacional.

1. Convenio suscrito con Chile.

2. Convenio suscrito con Canadá.

3. Convenio suscrito con la Comunidad Andina.

4. Convenio suscrito con Brasil.

5. Convenio suscrito con México.

6. Convenio suscrito con Corea del Sur.

7. Convenio suscrito con Suiza.

8. Convenio suscrito con Portugal.

V. Conclusiones. 


\title{
RESUMEN:
}

El presente trabajo tiene por objetivo evidenciar la relevancia del régimen impositivo que grava los dividendos como un factor que incide en el clima de inversión del país, a propósito de la constante evolución en el tratamiento fiscal de los mismos y de la renta corporativa. En ese sentido, se analizará la política fiscal en torno a la gravabilidad de los dividendos, los aspectos críticos de su regulación actual, y el planeamiento fiscal internacional que se puede elaborar a partir de los convenios para evitar la doble imposición suscritos por el Perú.

Palabras clave: Dividendo, Impuesto a la Renta, Política Fiscal, Inversión, Accionistas.

\begin{abstract}
:
The objective of this paper is to demonstrate the relevance of the tax regime that taxes dividends as a factor that affects the investment climate of the country, regarding the constant evolution in their regulation and corporate income. In this sense, we will analyze the fiscal policy regarding the taxability of dividends, the critical aspects of the current regulation, and the international tax planning that can be developed based on the agreements to avoid double taxation signed by Peru.
\end{abstract}

Keywords: Dividend, Income Tax, Fiscal Policy, Investment, Shareholders.

\section{TRATAMIENTO FISCAL APLICABLE LA INVERSIÓN PRIVADA NACIONALY EXTRANJERA}

La existencia de un tratamiento fiscal igualitario para las inversiones privadas nacionales $y$ extranjeras en nuestro ordenamiento jurídico tiene como sustento lo dispuesto en el artículo 63 de la Constitución Política del Perú. En línea con ello, el artículo 74 de la misma norma señala que al ejercer su potestad tributaria, el Estado debe respetar los principios de reserva de ley, igualdad, respeto a los derechos fundamentales de las personas, y no confiscatoriedad.

Por excepción, el artículo 71 de la Constitución Política del Perú establece un tratamiento diferenciado a la inversión extranjera en lo relativo a su derecho de propiedad, basado en razones de seguridad nacional. Es así que, dentro de cincuenta kilómetros de las fronteras, los extranjeros no pueden adquirir ni poseer, por título alguno, minas, tierras, bosques, aguas, combustibles ni fuentes de energía, directa ni indirectamente, individualmente ni en sociedad, bajo pena de perder, en beneficio del Estado, el derecho así adquirido. Se exceptúa el caso de necesidad pública expresamente declarada por decreto supremo, aprobado por el Consejo de Ministros conforme a ley.

De lo anterior se desprende que el Estado - por regla general- otorga un trato igualitario a las inversiones nacionales y extranjeras, el mismo que se manifiesta - entre otros-mediante el reconocimiento del "principio de igualdad fiscal" como límite a su potestad tributaria, a fin de que la carga tributaria sea aplicada de forma simétrica atendiendo a la capacidad contributiva de los sujetos, mas no a su lugar de domicilio o a cualquier otra condición subjetiva. En esa misma línea, el Tribunal Constitucional ha señalado que la potestad tributaria del Estado:

“(...) se encuentra directamente conectada con el derecho de igualdad en materia tributaria o, lo que es lo mismo, con el principio de capacidad contributiva, según el cual, el reparto de los tributos ha de realizarse de forma tal que se trate igual a los iguales $y$ desigual a los desiguales, por lo que las cargas tributarias han de recaer, en principio, donde exista riqueza que pueda ser gravada, lo que evidentemente implica que se tenga en consideración la capacidad personal o patrimonial de los contribuyentes"1.

1. Tribunal Constitucional, sentencia del 19 de julio del 2010, recaída en el Expediente № 2727-2002-AA/TC, fundamento jurídico 4. 
Esta misma interpretación ha sido reiterada en el Decreto Legislativo 662, Ley de Promoción de Inversión Extranjera, que reconoce ciertas garantías a las inversiones extranjeras, y el Decreto Legislativo 757, Ley Marco para el Crecimiento de la Inversión Privada, que otorga beneficios a las inversiones privadas nacionales y extranjeras.

El Decreto Legislativo 662 tiene como objetivo promover y garantizar las inversiones extranjeras efectuadas y por efectuarse en el país, en todos los sectores de la actividad económica y en cualquiera de las formas empresariales o contractuales permitidas por la legislación nacional. En ese sentido, en su artículo 2 establece que los inversionistas extranjeros y las empresas en las que estos participan tienen los mismos derechos y obligaciones que los inversionistas y empresas nacionales, sin más excepciones que las que establecen la Constitución Política del Perú y el mismo Decreto Legislativo. Dicho artículo agrega que, en ningún caso, el ordenamiento jurídico nacional discriminará entre inversionistas ni entre empresas en función a la participación nacional o extranjera en las inversiones.

Por su parte, el Decreto Legislativo 757 tiene como objetivo garantizar la libre iniciativa y las inversiones privadas, efectuadas o por efectuarse, en todos los sectores de la actividad económica y en cualquiera de las formas empresariales o contractuales permitidas por la Constitución y las Leyes. Asimismo, esta norma establece derechos, garantías y obligaciones que son de aplicación a todas las personas naturales o jurídicas, nacionales o extranjeras, que sean titulares de inversiones en el país.

En atención a lo anterior, el artículo 5 del citado Decreto Legislativo señala expresamente que el Estado garantiza el pluralismo económico, es decir, toda empresa tiene el derecho a organizarse bajo cualquier forma empresarial en la legislación nacional. No pudiendo limitarse el acceso directo o indirecto de los inversionistas o las empresas en que estos participen a actividades económicas específicas, en función a la forma empresarial que adopten. Más aún, el artículo 12 de la citada norma proscribe que el Estado establezca cualquier tipo de trata- miento discriminatorio o diferenciador entre los inversionistas y las empresas en que estos participen, basándose en sectores o tipo de actividad económica o en la ubicación geográfica de las empresas. Esto se extiende a las personas naturales nacionales o extranjeras.

Es así que las disposiciones de los Decretos Legislativos 662 y 757, que se encargan de promover la inversión privada en el país, no establecen excepciones basadas en la nacionalidad de los inversionistas o su ubicación geográfica, ni en la actividad que realizan o la forma societaria bajo la cual la realizan.

En materia fiscal, el Título Il del Decreto Legislativo 662 y el Título V del Decreto Legislativo 757 disponen que el Estado podría suscribir Convenios de Estabilidad Jurídica con los inversionistas privados -nacionales o extranjeros- con el objetivo de garantizar que la utilidad que presumen obtener por sus inversiones en el país no se verá afectada por posibles cambios en la estructura impositiva del país. En el mismo sentido, en regímenes sectoriales como los regulados por la Ley General de Minería - Texto Único Ordenado aprobado por Decreto Supremo № 14-92-EM-, Ley Orgánica de Hidrocarburos - Ley 26221-, Ley de Concesiones para Obras Públicas de Infraestructura y de Servicios Públicos - Texto Único Ordenado aprobado por Decreto Supremo №59-96-PCM - se reconoce a los titulares múltiples beneficios, entre los que se encuentran la estabilidad tributaria.

De otro lado, el artículo 10 del Decreto Legislativo 757 dispone que el Estado garantiza el derecho a las empresas, cualquiera que sea la forma empresarial que adopten, a acordar libremente la distribución del íntegro de las utilidades o dividendos que generen, y el derecho de los inversionistas a recibir la totalidad de los que les correspondan, inclusive los referidos al ejercicio en curso de acuerdo a balances periódicos, sin perjuicio de las obligaciones concernientes a la participación de los trabajadores, la reserva legal y las responsabilidades del caso conforme a lo establecido en la Ley General de Sociedades, siempre que se cumplan con las obligaciones tributarias pertinentes.

Cabe precisar que el "principio de igualdad fiscal" que se desprende del texto antes citado,

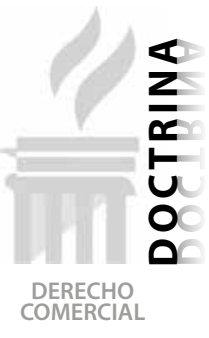

COMERCIAL

.


no implica una protección arbitraria ante el trato fiscal diferenciado basado en la capacidad contributiva de los inversionistas, es decir, no supone un trato ciego y uniforme a la inversión privada extranjera frente a la inversión privada nacional, ya que podría traducirse en una imposición más gravosa para el primero, si no se tiene en consideración que la carga tributaria total, que es soportada por los inversionistas extranjeros, también se encuentra determinada por los impuestos extranjeros de su país de origen.

En ese sentido, Van Hoorn señala que:

\begin{abstract}
"El aspecto que debe ser enfatizado en el contexto del contenido del tema es que la situación de los residentes y la de los no residentes es, por definición, desigual. No hay una base universal y común de comparación. Será necesario, por lo tanto, encontrar ciertos elementos comunes y analizar aquellas situaciones que carecen de tales elementos"2.
\end{abstract}

Así, por ejemplo, el artículo 14 de la Ley del Impuesto a la Renta no establece distinción en el tratamiento fiscal que deba otorgarse a las sociedades constituidas en el país en razón al origen de su capital —nacional o extranjero-, así se dispone que son contribuyentes del impuesto las sociedades que bajo cualquier forma societaria se hubieran constituido en el país.

Desde una perspectiva fiscal internacional, los Convenios bilaterales para Evitar la Doble Imposición suscritos entre el Perú y el país de origen de algunos inversionistas extranjeros - Chile, Canadá, Comunidad Andina, Brasil, México, Corea del Sur, Suiza y Portugal $-{ }^{3}$ otorgan luces también de hacia dónde debe apuntarse en aplicación del "principio de igualdad fiscal" para evitar que se produzca un tratamiento fiscal discriminatorio entre los inversionistas nacionales y extranjeros.

Este tipo de Convenios incluyen el "principio de no discriminación" como manifestación del "principio de igualdad fiscal" descrito anteriormente. Así, por ejemplo, en el párrafo 3 del artículo 24 del Modelo de Convenio para Evitar la Doble Imposición elaborado por el Comité de Asuntos Fiscales de la Organización para la Cooperación y Desarrollo Económico —en adelante, "OCDE" se señala que:

"Los impuestos que graven un establecimiento permanente de una empresa de un Estado contratante tenga en el otro Estado contratante no podrán ser menos favorables en ese otro Estado que los aplicables a las empresas de ese otro Estado que se dediquen a las mismas actividades (...)".

Este principio, en base al cual se estructura los Convenios bilaterales para Evitar la Doble Imposición, se aplica a las relaciones fiscales mucho antes de la aparición de este tipo de Convenios, así en los comentarios al Modelo de Convenio OCDE se señala que, desde el siglo $\mathrm{XIX}$, se plasma mediante convenios consulares, tratados de comercio, entre otros, evidenciando que los Estados guardan especial preocupación en reforzar y extender la protección diplomática a sus nacionales mediante el compromiso de otros Estados contratantes de procurar a unos y otros súbditos igualdad de trato.

Así, el "principio de no discriminación" en materia fiscal tiene por finalidad evitar la aplicación de medidas de proteccionismo fiscal que

2. VAN HOORN JR., J. "Diferencias en el tratamiento fiscal entre Inversionistas Nacionales y Extranjeros y Efecto de los Convenios Internacionales", Cuaderno Tributario № 10. Lima: Asociación Fiscal Internacional —IFA— Grupo Peruano, 1990, p. 68.

3. Los Convenios bilaterales para Evitar la Doble Imposición suscritos por el Perú que se encuentran vigentes constituirían normas con rango de ley que forman parte del ordenamiento jurídico nacional. Esta interpretación se desprendería del artículo 200 de la Constitución Política del Perú, cuando dispone que la acción de inconstitucionalidad procede contra las normas que tienen rango de ley, entre ellas, los tratados. Asimismo, el artículo 55 del mismo dispositivo establece que los tratados celebrados por el Estado y en vigor forman parte del derecho nacional. 
puedan servir para dificultar a los inversionistas extranjeros a través de una carga fiscal más onerosa, permitiendo que puedan competir a la par con los inversionistas nacionales que se encuentran en las mismas condiciones ${ }^{4}$. Encontrándose prohibidas las medidas discriminatorias en materia fiscal en razón de la nacionalidad de los inversionistas, al existir reciprocidad los nacionales de un Estado contratante, no pueden recibir en el otro Estado contratante un trato menos favorable que el aplicado a los nacionales de este último Estado que se encuentren en las mismas condiciones.

Como puede apreciarse, en el Perú se garantiza un tratamiento fiscal igualitario a los inversionistas extranjeros y nacionales lo cual no enerva que en atención a la particularidad de la situación fiscal de los inversionistas extranjeros se introduzcan consideraciones fiscales diferenciadas respecto a los mismos - como se explica más adelante respecto del régimen de dividendos - siempre que, como resultado final, la carga fiscal que soporta el inversionista extranjero le permita competir bajo las mismas condiciones con los inversionistas nacionales.

\section{POLÍTICA FISCAL EN TORNO A LA GRAVABILIDAD DE LOS DIVIDENDOS}

\section{Breve descripción del método de gravabilidad.}

A continuación, se analizan los métodos de gravabilidad a los dividendos adoptados en el Perú a lo largo del tiempo.

\subsection{Doble imposición económica e integración impositiva.}

Entre 1982 y 1993 estuvo vigente el régimen del Impuesto a la Renta, aprobado a través del
Decreto Legislativo 200 y normas modificatorias, mediante el cual las rentas empresariales se encontraron afectas al impuesto a la renta en dos niveles: (i) a nivel de las personas jurídicas que lo generaban y, (ii) a nivel de los accionistas cuando las utilidades eran distribuidas, quienes debían incluirlas en la determinación de su impuesto a la renta, permitiéndoseles deducir como crédito el importe retenido al momento de percibir el dividendo.

De lo anterior se evidencia que el legislador en materia fiscal recogió la teoría del ente separado o doble imposición sociedad-socio, que alentaba a las sociedades a retener utilidades en vez de repartirlas, a fin de evitar el impuesto a la renta que afectaba la distribución de dividendos. Vale la pena agregar que las personas jurídicas domiciliadas estaban sujetas a una tasa progresiva con un tope máximo del $55 \%$ mientras que la tasa - de carácter proporcional-aplicable a los dividendos era de $30 \%$.

\section{Tasas del Impuesto aplicable Decreto Legislativo 200}

\begin{tabular}{|c|c|c|}
\hline \multicolumn{2}{|c|}{$\begin{array}{c}\text { Escala de la tasa del impuesto a la } \\
\text { renta empresarial }\end{array}$} & $\begin{array}{c}\text { Tasa del impuesto } \\
\text { a la renta a los } \\
\text { dividendos }\end{array}$ \\
\hline Hasta 150 UIT ${ }^{5}$ & $30 \%$ & \\
\hline $\begin{array}{c}\text { Exceso de } 150 \text { UIT- Hasta } \\
1500 \text { UIT }\end{array}$ & $40 \%$ & \multirow{2}{*}{$30 \%$} \\
\cline { 1 - 1 } $\begin{array}{c}\text { Exceso de 1500 UIT - Hasta } \\
\text { 3000 UIT }\end{array}$ & $50 \%$ & \\
\hline Exceso de 3000 UIT & $55 \%$ & \\
\hline
\end{tabular}

Sin perjuicio de lo anterior, la opción legislativa descrita sufrió una modificación importante con el Decreto Legislativo 399, que estableció que los dividendos repartidos a los accionistas domiciliados - entiéndase personales naturales y jurídicas - no estarían sujetos a retenciones en la fuente al momento de su reparto a partir del

4. CALDERÓN CARRERO, José Manuel y MARTÍN JIMÉNEZ, Adolfo J. "La armonización jurisprudencial de la imposición directa: Las implicancias fiscales del principio comunitario de no discriminación por razón de la nacionalidad". En: Manual de Fiscalidad Internacional. Madrid: Instituto de Estudios Fiscales, 2001, p. 665.

5. La Unidad Impositiva Tributaria - UIT- es un valor referencial que puede ser utilizado en las normas tributarias. Su valor es determinado anualmente. Durante el año 1993, la UIT ascendió a S/ 1,700.00 —Mil Setecientos con $00 / 100$ Soles-. 
01 de enero de 1987, lográndose la neutralidad en la decisión de repartir utilidades.

Asimismo, a partir de la vigencia del mencionado Decreto Legislativo, se otorgó a las personas naturales beneficiarias del dividendo un crédito para ser aplicado contra el impuesto a la renta a su cargo, equivalente al incremento originado en el impuesto determinado para el ejercicio por la incorporación de los dividendos, el cual no podía exceder del $29.5 \%$ del monto de los dividendos. Si el monto del impuesto determinado resultaba menor que el crédito, el accionista - persona natural- no pagaba el impuesto, con lo cual, la renta de la sociedad sólo estaba gravada en cabeza de esta.

Tasas aplicables

Decreto Legislativo 399

\begin{tabular}{|c|c|c|c|}
\hline \multicolumn{2}{|c|}{$\begin{array}{c}\text { Escala de la tasa del } \\
\text { impuesto a la renta neta } \\
\text { global de las personas } \\
\text { naturales }\end{array}$} & $\begin{array}{l}\text { Tasa del im- } \\
\text { puesto a la } \\
\text { renta a los } \\
\text { dividendos } \\
\end{array}$ & $\begin{array}{c}\text { Tasa del } \\
\text { impuesto } \\
\text { a la renta } \\
\text { empresarial }\end{array}$ \\
\hline Hasta 15 UIT & $8 \%$ & \multirow{9}{*}{$15.4 \%$} & \multirow{9}{*}{$35 \%$} \\
\hline $\begin{array}{c}\text { Exceso de } 15 \text { UIT- } \\
\text { Hasta } 20 \text { UIT }\end{array}$ & $10 \%$ & & \\
\hline $\begin{array}{l}\text { Exceso de } 20 \text { UIT - } \\
\text { Hasta } 25 \text { UIT }\end{array}$ & $12 \%$ & & \\
\hline $\begin{array}{c}\text { Exceso de } 25 \text { UIT - } \\
\text { Hasta } 33 \text { UIT }\end{array}$ & $16 \%$ & & \\
\hline $\begin{array}{c}\text { Exceso de } 33 \text { UIT - } \\
\text { Hasta } 41 \text { UIT }\end{array}$ & $20 \%$ & & \\
\hline $\begin{array}{c}\text { Exceso de } 41 \text { UIT - } \\
\text { Hasta } 50 \text { UIT }\end{array}$ & $25 \%$ & & \\
\hline $\begin{array}{c}\text { Exceso de } 50 \text { UIT - } \\
\text { Hasta } 60 \text { UIT }\end{array}$ & $31 \%$ & & \\
\hline $\begin{array}{c}\text { Exceso de } 60 \text { UIT - } \\
\text { Hasta } 72 \text { UIT }\end{array}$ & $38 \%$ & & \\
\hline Exceso de 72 UIT & $45 \%$ & & \\
\hline
\end{tabular}

Como puede observarse, el régimen fiscal vigente en ese momento adoptó paralelamente la teoría de la integración del impuesto al vincular el impuesto a la renta de la sociedad con el que correspondía al accionista.

Más tarde, se introdujo una modificación menor al régimen fiscal con el Decreto Legislativo 618 vigente a partir del 01 de enero de 1991, a través de la cual la tasa del impuesto a la renta de la sociedad se fijó en $30 \%$ y en $10 \%$ en el caso de dividendos pagados a personas naturales.

\subsection{Imposición a nivel de personas jurídicas e incentivo a la reinversión de utilidades.}

Ahora bien, es con la dación del Decreto Legislativo 774, que aprobó el texto del nuevo régimen del impuesto a la renta vigente a partir del ejercicio 1994, que se modifica radicalmente el régimen fiscal aplicable a los dividendos, eliminándose la imposición a dos niveles de las rentas empresariales - doble imposición económica- predominante en la legislación.

Así, el artículo 25 del Decreto Legislativo 774 estableció que los dividendos y cualquier forma de distribución de utilidades no constituían renta gravable, por lo tanto, las rentas empresariales obtenidas por las personas jurídicas sólo se gravaban a nivel de las personas jurídicas que lo generaban, mas no a nivel de los accionistas.

La tasa impositiva aplicable a las rentas empresariales obtenidas por las personas jurídicas por el período comprendido entre 1994 a 2000 fue de $30 \%$. La misma tasa impositiva fue aplicable a las personas naturales por sus rentas empresariales - manteniendo el sistema de exención a la distribución de dividendos-, mientras que a sus demás rentas se les aplicaba una tasa progresiva de $15 \%$ y $30 \%$.

Posteriormente, con las Leyes 27394 y 27513 se modifica la tasa impositiva aplicable a las rentas empresariales a $20 \%{ }^{6}$ en el ejercicio 2001 y luego a $27 \%$ en el ejercicio 2002. Adicionalmente, a fin de incentivar la reinversión y la capitalización de las utilidades de sociedades domiciliadas en el país, se dispuso que si las mismas distribuían total o parcialmente utilidades debían aplicar una tasa adicional de $4.1 \%$ sobre el monto dis-

6. Durante el ejercicio 2001, las rentas empresariales se encontraban gravadas -en principio- con la tasa impositiva del $30 \%$, sujeta a una reducción de $10 \%$ siempre que el monto deducido fuera invertido en el país en cualquier sector de la actividad económica del país. 
tribuido, salvo que la distribución sea efectuada a favor de otra sociedad domiciliada.

Sin embargo, este pago de carácter definitivo de $4.1 \%$ que debía ser efectuado por el sujeto domiciliado generador de rentas empresariales de tercera categoría y, por ende, generador de utilidades, no podía ser deducido como crédito contra su impuesto a pagar. Por su parte, la tasa aplicable a las personas naturales también fue modificada en el ejercicio 2002 pasando a una nueva tasa progresiva en tres tramos de $15 \%, 21 \%$ y $27 \%$.

\subsection{Doble imposición económica e imposición cedular.}

Un nuevo giro en el régimen de imposición a los dividendos fue dado con la aprobación de la Ley 27804 , vigente a partir del ejercicio 2003, puesto que los dividendos distribuidos vuelven a encontrarse gravados en cabeza de los accionistas - receptor-con una tasa de $4.1 \%$. No obstante, a diferencia del régimen del Decreto Legislativo 200 , se establece una imposición de tipo cedular sobre dichas rentas evitando que se integre a la renta neta global de las personas naturales, es decir, las mismas no son susceptibles de ser integradas a las demás rentas de los accionistas y tampoco genera el derecho de crédito alguno.

Con este nuevo esquema del impuesto a la renta de la sociedad y el impuesto a los dividendos de cargo del accionista se busca generar una redistribución de la carga económica del impuesto a la renta que bajo el esquema del Decreto Legislativo 774 recaía únicamente a nivel de la sociedad encontrándose inafecta la distribución de dividendos? ${ }^{7}$.

Conforme a lo expuesto, en el artículo 92 del Reglamento de la Ley del Impuesto a la Renta, incorporado mediante Decreto Supremo No 17-2003-EF, se dispone que la tasa de $4.1 \%$ que grava los dividendos o cualquier otra forma de distribución de utilidades es de aplicación general e independiente a la tasa del impuesto a la renta a cargo de la persona jurídica que efectúa la distribución. Precisándose de esa manera, que el contribuyente del impuesto a los dividendos es el perceptor de los dividendos o utilidades distribuidas - accionista persona natural o sujeto no domiciliado-, en tanto la persona jurídica que efectúa la distribución actúa como agente de retención del impuesto a los dividendos.

Es así que la tasa del Impuesto a la renta correspondiente a las rentas empresariales de las personas jurídicas se fijó en $27 \%$-eliminándose la tasa adicional del $4.1 \%$ prevista para el ejercicio 2002 - y la tasa aplicable a los perceptores de dividendos y cualquier otra forma de distribución se fijó en 4.1\%. De otro lado, de acuerdo a la Ley 27895, publicada en diciembre de 2002, se incrementó a $30 \%$ la tasa progresiva máxima aplicable a las rentas de personas naturales.

En este punto, es pertinente señalar que conforme a la Exposición de Motivos del Proyecto de Ley 3223 que sustenta las modificaciones introducidas por la Ley 27804 , la razón que justificó la modificación de la tasa impositiva del $4.1 \%$ sobre los dividendos fue la siguiente:

"De la regulación actual - Ley 27513-no queda claro si la denominada tasa adicional responde a un nuevo tributo o si es una simple tasa adicional del propio Impuesto a la Renta de la empresa, pudiendo ser distintas las consecuencias en uno u otro caso. De ahí que, a la fecha la tasa adicional resulte de imposible aplicación debido a la ausencia de normas que definan el contenido del término "utilidades" $y$, por lo tanto, no existe una base de cálculo sobre la cual aplicar la tasa adicional. El Proyecto aclara que se trata de un impuesto sobre el dividendo u otras formas de distribución de utilidades, siendo el monto del reparto la base de cálculo sobre la que debe aplicarse la tasa del 4.1\%. La empresa que acuerda la distribución será agente retenedor del impuesto de cargo del beneficiario. La retención tiene carácter definitivo" (subrayado agregado).

7. Más adelante se evidenciará que dicha distribución es imperfecta en algunos casos. 
Conforme a lo anterior, con este nuevo esquema fiscal para los dividendos se pretende subsanar errores de la Ley 27513 y aclarar que la tasa del $4.1 \%$ sobre los dividendos no es una tasa adicional de cargo de la persona jurídica, sino que se trata de una tasa correspondiente a un nuevo tributo en cabeza de los accionistas, siendo que la persona jurídica, que inicialmente fue considerada contribuyente, ahora pasa a calificar como agente de retención del impuesto a los dividendos; precisándose incluso en la Tercera Disposición Final y Transitoria de la Ley 27804 que la tasa adicional no entraría en vigor para el ejercicio 2002.

En ese sentido, el $4.1 \%$ que se aplicaba a la distribución de dividendos era retenido por la persona jurídica que paga el impuesto con carácter definitivo a nombre del beneficiario. Pudiendo ser el beneficiario una persona natural o sucesión indivisa domiciliada, así como un sujeto no domiciliado - persona natural o jurídica-. En caso el perceptor del dividendo fuera una persona jurídica domiciliada a ésta no se le retendría -ingreso inafecto hasta que se produzca la distribución a una persona natural o sujeto no domiciliado-.

Asimismo, otro aspecto de la legislación anterior que se subsanó con la Ley 27804 fue la aplicación de la tasa del $4.1 \%$, pues derogó la disposición de la Ley 27513 referida a la definición del término "utilidades" para definir con mayor precisión la base de cálculo sobre la cual aplicar la denominada tasa adicional. Es así que se incorpora el artículo 24-A a la Ley del Impuesto a la Renta estableciéndose la definición de "dividendos y cualquier otra forma de distribución de utilidades", respecto de la cual se comentará más adelante.

Nótese que la definición de dividendos del citado artículo 24-A contempló un inciso g), referido a un supuesto por el cual toda suma o entrega en especie que, al practicarse la fiscalización respectiva ${ }^{8}$, resulte renta gravable de tercera categoría, siempre que el egreso por su naturaleza signifique una disposición indirecta de dicha renta no susceptible de posterior control tributario. En este caso, se generaba para la persona jurídica un pago adicional de $4.1 \%$ de cargo de la misma. En otras palabras, de configurarse este supuesto, además del $27 \%$, la persona jurídica se encontraría obligada al pago del impuesto con una tasa adicional de $4.1 \%$.

Cabe mencionar que, mediante el Decreto Legislativo 945, a partir del ejercicio 2004 se modificó la tasa impositiva a la renta empresarial de las personas jurídicas, encontrándose gravadas con un impuesto a la renta de $30 \%$. No obstante, en dicha oportunidad no se establecieron modificaciones respecto de la tasa aplicable a los dividendos y la tasa adicional del $4.1 \%{ }^{9}$.

\section{2. Últimas modificaciones tributarias.}

Las últimas modificaciones tributarias se han concentrado en una reforma combinada de las tasas impositivas del impuesto a la renta empresarial de los contribuyentes domiciliados, y de los dividendos y cualquier otra forma de distribución de utilidades de fuente peruana, con el objetivo de reactivar la economía del país mediante una mayor recaudación tributaria.

Es así que, mediante la Ley 30296, a partir del 01 de enero del 2015 se modifican de forma paralela y progresiva las tasas impositivas correspondientes a las rentas empresariales de las personas jurídicas domiciliadas, y a los dividendos y cualquier otra forma de distribución de utilidades de fuente peruana. Por un lado, se efectuó una rebaja escalonada de la tasa aplicable a las rentas

8. Hasta el 31 de diciembre de 2006, la recaudación efectuada por la Administración Tributaria de la tasa adicional del $4.1 \%$ no se llegaba a concretar puesto que era un requisito que para que se origine el dividendo presunto debería realizarse una fiscalización. Es mediante el Decreto Legislativo 970 vigente a partir del 01 de enero de 2007 que se elimina el requisito de la "fiscalización", configurándose la obligación de pagar la tasa adicional del 4.1\% de manera inmediata, en consecuencia, dentro del mes siguiente de haberse efectuado la disposición indirecta de renta no susceptible a control tributario se tenía que depositar al fisco el impuesto respectivo. Más adelante se hará una referencia a este supuesto.

9. La tasa del $4.1 \%$ sería aplicable a los acuerdos de distribución de dividendos u otras formas de utilidades que se adopten a partir del 1 de enero de 2003, incluso si dichos acuerdos se refieren al año 2002 u otro anterior. 
empresariales de cargo de las personas jurídicas de $28 \%$ durante los ejercicios 2015-2016, 27\% durante los ejercicios 2017-2018, y 26\% durante el ejercicio 2019 en adelante.

Mientras que de otro lado, se incrementó escalonadamente la tasa aplicable a los dividendos y cualquier otra forma de distribución de utilidades disponiéndose que será de $6.8 \%$ durante los ejercicios 2015-2016, 8\% durante los ejercicios 2017-2018, y 9.3\% durante el ejercicio 2019 en adelante $^{10}$. Un supuesto de excepción es el de disposición indirecta de renta no susceptible de control tributario -inciso g) del artículo 24-A de la Ley del Impuesto a la Renta-, en cuyo caso los dividendos presuntos continuaron gravados con la tasa adicional del $4.1 \%$.

La justificación para dichas modificaciones se encontró en la Exposición de Motivos del Proyecto de Ley 3922, donde el legislador resaltaba que en el caso de Perú, la tasa del impuesto a la renta aplicable a las personas jurídicas era de $30 \%$, la cual era una de las tasas impositivas más altas de la región latinoamericana. En ese sentido, una reducción de la mencionada tasa impositiva debería estar acompañada del incremento gradual de la tasa del impuesto a la renta aplicable a los dividendos para mantener constante la carga tributaria.

En esa misma línea, en la Exposición de Motivos se señalaba:

"En efecto, la reducción gradual de la tasa del Impuesto a la Renta aplicable a las personas jurídicas en el Perú incrementará la competitividad de nuestro país respecto a otros países de la región, aumentaría los niveles de inversión doméstica y atraerá la inversión extranjera. Es necesario asegurar que dicha modificación no afecte la actual carga tributaria, estimada en 33\% - considerando el gravamen a los dividendos-".

Sin embargo, a pesar de las reformas introducidas no se logró acelerar las inversiones en el país durante el 2015 y 2016, es decir, no se promovió la reinversión de utilidades de las empresas y no se atrajo inversión extranjera dado que desde el año 2012 se experimentó una reducción en la tasa de crecimiento de la inversión bruta fija privada, siendo que en el año 2014 dicha tasa fue negativa e igual a $2.3 \%$.

\section{Inversión bruta fija privada, 2010 - 2016 (primer trimestre) ${ }^{11}$ (\% del PBI y Var. \% Real)}

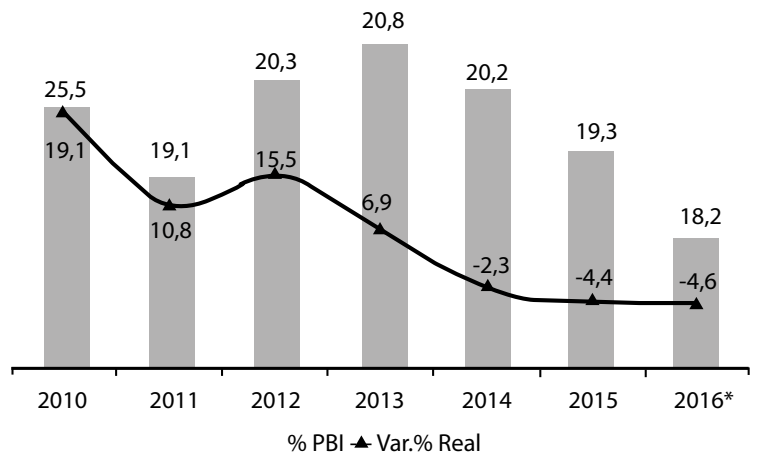

Bajo ese contexto, con la Ley 30506 de fecha 09 de octubre de 2016, se delegaron facultades al Poder Ejecutivo para legislar en materia de reactivación económica con el objetivo entre otros- de ampliar la base tributaria e incentivar la formalización a través de la modificación de las tasas impositivas del impuesto a la renta empresarial de los contribuyentes domiciliados y a los dividendos y cualquier otra forma de distribución de utilidades de fuente peruana.

10. De acuerdo a la Novena Disposición Complementaria Final de la Ley 30296, las tasas establecidas en dicho dispositivo se aplican a la distribución de dividendos y otras formas de distribución de utilidades que se adopten o se pongan a disposición en efectivo o en especie, lo que ocurra primero, a partir del 1 de enero de 2015. A los resultados acumulados u otros conceptos susceptibles de generar dividendos gravados, a que se refiere el artículo 24-A de la Ley del Impuesto a la Renta, obtenidos hasta el 31 de diciembre de 2014 que formen parte de la distribución de dividendos o de cualquier otra forma de distribución de utilidades se les aplicará la tasa de cuatro coma uno por ciento -4,1\%.

11. Extraído de la Exposición de Motivos del Decreto Legislativo 1261, norma que modifica la Ley del Impuesto a la Renta, p. 2. Se toma como fuente datos del Banco Central de la Reserva del Perú y el Ministerio de Economía y finanzas. 
En tal sentido, con fecha 10 de diciembre de 2016 se aprobó el Decreto Legislativo 1261, mediante el cual se llevó a cabo las modificaciones de las tasas impositivas antes mencionadas, las mismas que entraron en vigencia el 01 de enero de 2017. Como consecuencia de lo anterior, se dejó sin efecto la reducción progresiva de la tasa aplicable a las rentas empresariales y el incremento progresivo de la tasa aplicable a los dividendos y cualquier otra forma de distribución de utilidades.

Conforme a la Exposición de Motivos dichos cambios se justificaron en lo siguiente:

"No obstante, a la fecha se ha observado que la reducción del impuesto a la renta empresarial y el incremento de la tasa del impuesto a la renta aplicable a los dividendos de fuente peruana no han cumplido con su objetivo pues no se logró incrementar los niveles de inversión doméstica. (...) la inversión bruta fija privada disminuyó en $4.4 \%$ y $4.6 \%$ en los años 2015 y 2016, respectivamente. Además, dado que los dividendos no necesariamente se distribuyen en los ejercicios en que se generan, sino que la distribución suele ser posterior, existe la posibilidad de que la carga combinada aplicada sobre una misma renta en períodos diferentes alcance niveles superiores a 33\%".

Sumado a lo anterior, otra razón que justificó una nueva modificación de las tasas impositivas fue la disminución en la recaudación como consecuencia de la reducción de la tasa del impuesto a la renta empresarial. Así, en la Exposición de Motivos se señala que:
"En efecto, bajo las condiciones vigentes se ha estimado una pérdida para el año 2016 de S/ 1300 millones - diferencia entre la pérdida de S/ 1600 millones correspondiente al impuesto a la renta empresarial y la ganancia de S/ 300 millones por dividendos-. Adicionalmente, en el año 2017 dicha pérdida sería mayor o igual a $\mathrm{S} /$. 2580 millones y en los próximos años ésta se haría más significativa en la medida de que se aplique el cronograma previsto de reducción de tasas".

Por tanto, con el objetivo de solucionar la problemática expuesta, se redujo la tasa impositiva aplicable a los dividendos y otras formas de distribución de utilidades, a cargo de personas naturales domiciliadas o no en el país, y de personas jurídicas no domiciliadas, de $6.8 \%$ a $5 \%^{12}$. Siendo que en paralelo, a fin de garantizar que la carga tributaria se mantenga, se incrementó a $29.5 \%$ la tasa del impuesto a la renta empresarial de las personas jurídicas domiciliadas.

Téngase en cuenta que en el caso de personas jurídicas que realicen disposición indirecta de renta, se modificó también la tasa impositiva adicional que grava la entrega de dividendos presunto de $4.1 \%$ a $5 \%$.

A modo de resumen, resulta relevante establecer gráficamente cuál ha sido la evolución fiscal del impuesto a la renta de cargo de las sociedades y de los dividendos de cargo de los accionistas - personas naturales-.

12. De acuerdo a la Tercera Disposición Complementaria Final del Decreto Legislativo 1261, la tasa establecida en dicho dispositivo se aplica a la distribución de dividendos y otras formas de distribución de utilidades que se adopten o se pongan a disposición en efectivo o en especie, lo que ocurra primero, a partir del 1 de enero de 2017. A los resultados acumulados u otros conceptos susceptibles de generar dividendos gravados, a que se refiere el artículo 24-A de la Ley del Impuesto a la Renta, obtenidos entre el 01 de enero del 2015 y el 31 de diciembre de 2016 que formen parte de la distribución de dividendos o de cualquier otra forma de distribución de utilidades se les aplicará la tasa de seis como ocho por ciento -6,8\%-.

De otro lado, la Cuarta Disposición Complementaria Final del Decreto Legislativo 1261, a efectos de aplicar lo dispuesto en la disposición anterior y la Novena Disposición Complementaria Final de la Ley 30296 establece como presunción - sin admitir prueba en contrario-que la distribución de dividendos o de cualquier otra forma de distribución de utilidades corresponde a los resultados acumulados u otros conceptos susceptibles de generar dividendos gravados más antiguos. 
Evolución del sistema fiscal a los dividendos en el país

\begin{tabular}{|c|c|c|c|}
\hline Norma Legal & $\begin{array}{l}\text { Período de } \\
\text { Vigencia }\end{array}$ & $\begin{array}{l}\text { Tasa del im- } \\
\text { puesto a la ren- } \\
\text { ta a las rentas } \\
\text { empresariales }\end{array}$ & $\begin{array}{l}\text { Tasa del im } \\
\text { puesto a la } \\
\text { renta a los } \\
\text { dividendos } \\
\end{array}$ \\
\hline \begin{tabular}{|c|} 
Decreto Legisla- \\
tivo 200 \\
\end{tabular} & $1982-1986$ & 55\% (máxima) & $30 \%$ \\
\hline \begin{tabular}{|c|} 
Decreto Legisla- \\
tivo 399 \\
\end{tabular} & $1987-1990$ & $35 \%$ & $15.4 \%$ \\
\hline \begin{tabular}{|c|} 
Decreto Legisla- \\
tivo 618 \\
\end{tabular} & $1991-1993$ & $30 \%$ & $10 \%$ \\
\hline \begin{tabular}{|c|} 
Decreto Legisla- \\
tivo 774 \\
\end{tabular} & $1994-2000$ & $30 \%$ & Inafecto \\
\hline Ley 27394 & 2001 & $\begin{array}{l}30 \%(20 \% \\
\text { acreditando } \\
\text { reinversión) }\end{array}$ & Inafecto \\
\hline Ley 27513 & 2002 & $27 \%$ & Inafecto \\
\hline Ley 27804 & 2003 & $27 \%$ & $4.1 \%$ \\
\hline \begin{tabular}{|c|} 
Decreto Legisla- \\
tivo 945 \\
\end{tabular} & $2004-2014$ & $30 \%$ & $4.1 \%$ \\
\hline Ley 30296 & $2015-2016$ & $\begin{array}{c}28 \% \\
\text { (se reguló una } \\
\text { disminución } \\
\text { progresiva de la } \\
\text { tasa impositiva } \\
\text { a } 27 \% \text { durante } \\
\text { el } 2017-2018 \text { y } \\
\text { a } 26 \% \text { durante } \\
\text { el } 2019 \text { en } \\
\text { adelante) }\end{array}$ & \begin{tabular}{|c}
$6.8 \%$ \\
(se \\
reguló un \\
aumento \\
progresivo \\
de la tasa \\
impositi- \\
va a $8 \%$ \\
durante el \\
$2017-2018$ \\
y a $9.3 \%$ \\
durante el \\
2019 en \\
adelante)
\end{tabular} \\
\hline \begin{tabular}{|c|} 
Decreto Legisla- \\
tivo 1261
\end{tabular} & 2017 & $29.5 \%$ & $5 \%{ }^{13}$ \\
\hline
\end{tabular}

\section{RÉGIMEN IMPOSITIVO DE LOS DIVIDENDOS EN EL PAÍS}

Como se venía anotando, en nuestro régimen impositivo actual el impuesto a los dividendos no es aplicable a las personas jurídicas domiciliadas, las cuales no están sujetas a retención sobre los dividendos que perciban. Lo anterior se justifica en que dicho impuesto sí será aplicado cuando se efectúen redistribuciones a favor de personas naturales domiciliadas en el país o sujetos no domiciliados, de lo contrario, los dividendos estarían sujetos a una múltiple imposición generando un desincentivo a las personas jurídicas perceptoras de dividendos.

Sobre el concepto de "dividendos", nótese que en el artículo 24-A de la Ley del Impuesto a la Renta no se limita a su definición societaria referida a "las utilidades en efectivo o en especie distribuidas por personas jurídicas domiciliadas a las personas que la integran al cierre de un período"14, sino que en virtud de la autonomía del Derecho Tributario se han considerado supuestos adicionales para fines impositivos, tales como:

a) La distribución de "dividendos anticipados" o "dividendos a cuenta" que ocurre cuando "(...) antes de finalizar el ejercicio social una parte de las utilidades que se presume alcanzará la sociedad, se distribuye entre los socios como anticipo a cargo del dividendo que se espera se declare en el futuro"15.

Los "dividendos anticipados" se presentan como un crédito atípico otorgado por las sociedades a favor de sus accionistas, antes que se apruebe el balance de cierre final, que se deducirá del dividendo total que le corresponda. Dicha distribución es permitida por

13. Las disposiciones establecidas por el Decreto Legislativo 1261 no son aplicables a los inversionistas que hayan suscrito convenios de estabilidad jurídica al amparo de los Decretos Legislativos 662 y 757 y/o bajo leyes sectoriales, a menos que dichos inversionistas opten por renunciar a sus convenios de estabilidad jurídica a fin de que les resulte aplicable la tasa del $5 \%$ a los dividendos y de forma paralela: (i) la empresa receptora de las inversiones renuncie a su convenio de estabilidad suscrito, y (ii) los otros inversionistas de la empresa receptora renuncien a sus convenios de estabilidad suscritos. Lo anterior se justifica en que el objetivo de la medida es mantener la carga tributaria de $33 \%$.

14. El artículo 40 de la Ley General de Sociedades señala que: "La distribución de utilidades sólo puede hacerse en mérito de los estados financieros preparados al cierre de un período determinado o a la fecha de corte en circunstancias especiales que acuerde el directorio. Las sumas que se repartan no pueden exceder el monto de las utilidades que se obtengan".

15. GUTIERREZ FALLA, Laureano. "Derecho Mercantil. Contrato societario y derechos individuales de los accionistas". Tomo I. Buenos Aires: Astrea, 1988, p. 436. 
nuestra legislación societaria ${ }^{16}$, siempre que sean realizadas sobre utilidades comprobadas y realmente obtenidas para no vulnerar el principio de integridad del capital social. Ello quiere decir que no puede distribuirse beneficios si no existe previamente un balance de la sociedad que efectivamente arroje las utilidades que se desea repartir -balance parcial que ordene especialmente el directorio-, teniendo en cuenta que las sumas a repartir no excedan el monto de las utilidades que se hayan logrado.

Lo anterior es comprendido por el legislador fiscal que precisa en el artículo 88 del Reglamento de la Ley del Impuesto a la Renta que el "adelanto de utilidades" tiene condición de dividendos - asimilado al inciso a) del artículo 24-A de la Ley del Impuesto a la Renta-, siendo que acordada la distribución será exigible el impuesto a la renta a los dividendos.

Al respecto, se desprende de la Resolución del Tribunal Fiscal № 14908-3-2011 17 que, a fin de efectuar el "adelanto de utilidades", será necesario no solo contar con el Acta de la Junta General de Accionistas donde se acuerde la distribución por adelantado de utilidades, sino que también será necesario contar con un Balance General con fecha del último día del mes anterior respecto al cual se acordó otorgar dividendos anticipados a los accionistas, a fin de efectuar sobre la base de los resultados una determinación real de los dividendos que se pretenden repartir. Este pronunciamiento reitera los criterios emitidos por el Tribunal Fiscal en las Resoluciones No 308-4-96 ${ }^{18}$, y No 08857-2-2007 ${ }^{19}$.

Al tener los "dividendos anticipados" naturaleza crediticia, es recomendable que aquellas sociedades que los repartan efectúen proyecciones financieras con el fin de no entregar "dividendos anticipados" superiores a los que en realidad podrían determinarse al cierre del ejercicio económico corriente, puesto que es de aplicación la presunción del artículo 26 de la Ley del Impuesto a la Renta de superar los "dividendos adelantados" a la utilidad distribuible, o de no obtenerse utilidad al cierre del ejercicio, debiendo reconocerse intereses presuntos por el exceso. Así, los Estados Finan-

16. Artículo 230 de la Ley General de Sociedades.

17. En dicho caso ni la Administración Tributario ni el Tribunal Fiscal cuestionaron la determinación de los "dividendos anticipados" conforme fue efectuada por el recurrente: "Que el recurrente sostiene que (...), el 13 de julio de 2006 se realizó una sesión de directorio mediante el cual se acordó otorgar dividendos a favor de cada uno de los accionistas por el importe de US\$53,973.00, que fueron acordados sobre la base de los resultados obtenidos según el Balance General al 30 de junio de 2006; y que posteriormente, el 10 de octubre de 2016, también en Sesión de Directorio se acordó otorgar dividendos a cuenta a favor de los accionistas por la suma de US\$270,000.00, determinados sobre la base de los resultados según Balance General al 30 de setiembre de 2006". La cuestión controvertida radicaba en la aplicación de la infracción del numeral 4 del artículo 178 del Código Tributario referida a no pagar los tributos retenidos dentro de los plazos establecidos.

18. En ese caso el Tribunal Fiscal validó el "adelanto de dividendos" realizado por el contribuyente en 1989, año en el que inició actividades, señalando lo siguiente: "Del análisis de los papeles de trabajo se aprecia que la recurrente de acuerdo a sus Estados Financieros Mensuales, ha obtenidos utilidades de manera constante (...) Los dividendos distribuidos fueron calificados como tales por acuerdo de las Juntas Generales de Accionistas, en las que se acordó la distribución de dividendos anticipados. Asimismo, se advierte que los dividendos repartidos no fueron por sumas mayores a las utilidades acumuladas hasta cada oportunidad y que las utilidades del ejercicio resultan mayores que la suma de los dividendos distribuidos. En consecuencia, procede levantar el reparo".

19. Respecto a los retiros de dinero a cuenta de utilidades, el Tribunal Fiscal afirmó lo siguiente: “(...) de conformidad con lo dispuesto por el artículo 40 de la Ley General de Sociedades, Ley 26887, la distribución de utilidades solo puede hacerse en mérito de los estados financieros preparados al cierre de un período determinado o la fecha de corte en circunstancias especiales que acuerde el directorio, y si bien procede la distribución de dividendos conforme lo dispuesto en el artículo 230 de la Ley General de Sociedades, dicha circunstancia no ha sido acreditada por la recurrente a pesar de habérsele requerido durante la fiscalización". 
cieros preparados al cierre del ejercicio en el que se efectúe el "adelanto de dividendos", y los medios de pago utilizados para el "pago adelantado de dividendos" constituyen documentación relevante a fin de soportar que los "dividendos adelantados" no superan a los obtenidos en el ejercicio.

b) La distribución, en efectivo o en especie, del mayor valor atribuido por revaluación de activos.

c) La reducción del capital, hasta por el importe equivalente a utilidades, excedente de revaluación o reservas de libre disposición capitalizados previamente, siempre que dicha reducción no se destine a cubrir pérdidas.

d) La diferencia entre el valor nominal de los títulos representativos de capital más las primas suplementarias, si las hubiere y los importes que perciban las personas que la integran, en la oportunidad en que opere la reducción de capital o la liquidación de la persona jurídica.

La razón mercantil por la cual un accionista puede recibir de una sociedad un importe superior al valor nominal de sus acciones es porque cuenta con utilidades o resultados acumulados, como consecuencia del desarrollo de su objeto social, que no han sido capitalizados pero que incrementan el valor patrimonial de la sociedad. Por tanto, los beneficios acumulados abonados al accionista ya sea a través de -entre otros- un "rescate de acciones" o consecuencia de la liquidación de la persona jurídica deben encontrarse sujetos al impuesto a la renta por parte de la sociedad.

Este mayor valor recibido por los accionistas no es consecuencia de la negociación que hubieran podido haber realizado con la sociedad emisora de los valores —en cuyo caso podríamos estar ante una ganancia de capital- sino que se origina en las actividades de la propia sociedad, que ha generado resultados positivos que se han ido acumulando en el tiempo. Por tanto, los beneficios obtenidos como consecuencia del "rescate de acciones"o de la liquidación de la persona jurídica tienen la naturaleza de dividendos.

En ambos casos, los accionistas deben entregar sus acciones en la parte pertinente o en su totalidad para que sean anuladas. A cambio de ello, la sociedad debe devolver los aportes efectuados o el patrimonio social. Si las devoluciones a favor de los accionistas superan el valor de sus aportes, la diferencia se encuentra sujeta a imposición como dividendos, debiendo para tales propósitos sumar a los aportes las primas suplementarias de capital si las hubiere.

Cabe precisar que, en la legislación societaria se define al "rescate de acciones" como la adquisición por parte de la sociedad emisora de sus propias acciones, ya sea para amortizarlas o para mantenerlas en cartera ${ }^{20}$. Constituye una figura sui generis que se distingue de una operación de compra de acciones porque es una excepción al impedimento de que las sociedades adquieran sus propios valores representativos de capital social, y se distingue de una simple reducción de capital toda vez que no necesariamente conlleva la devolución de capital a sus accionistas, puesto que los títulos representativos de capital pueden mantenerse en cartera para ser enajenados posteriormente o adquirirse exclusivamente con reservas de libre disposición sin reducción de capital.

Bajo ese entender, la naturaleza de "dividendos" del beneficio obtenido por el accionista se verifica en todos los casos de "rescate de acciones" tanto cuando se amortizan con

20. Artículo 104 de la Ley General de Sociedades. 
la respectiva reducción de capital, así como si se mantienen en cartera por el plazo y condiciones que establece la legislación societaria ya que como se menciona el mayor valor recibido sobre su inversión constituye rendimiento del mismo. Este mayor valor se encontrará gravado con el impuesto a los dividendos en caso el perceptor sea una persona natural domiciliada o un sujeto no domiciliado, mientras que si el beneficiario fuera una persona jurídica domiciliada tales beneficios sólo estarán sujetos al pago del impuesto cuando se redistribuyan a su vez entre sus socios.

e) La participación de utilidades que provenga de parte del fundador, acciones del trabajo y otros títulos que confieran a sus tenedores facultades para intervenir en la administración o en la elección de los administradores o el derecho a participar, directa o indirectamente, en el capital o en los resultados de la entidad emisora.

f) Todo crédito, hasta el límite de las utilidades y reservas de libre disposición, que las personas jurídicas que no sean empresas de operaciones múltiples o empresas de arrendamiento financiero otorguen en favor de sus socios, asociados, titulares o personas que las integran, según sea el caso, en efectivo o en especie, con carácter general o particular, cualquiera sea la forma dada a la operación y sin importar el plazo otorgado para su devolución ${ }^{21}$. Esta presunción no es aplicable a las operaciones de crédito en favor de trabajadores de la empresa que sean propietarios únicamente de acciones de inversión.
Al respecto, la Administración Tributaria en el Informe No 032-2017-SUNAT/5D000 señaló que esta presunción de distribución de dividendos no resulta aplicable al préstamo otorgado por una persona jurídica domiciliada en el país a favor de una persona jurídica no domiciliada que no tiene derecho a percibir tales utilidades, aun cuando pertenezca al mismo grupo económico y sea parte vinculada a la persona jurídica prestamista, pero que no es accionista. Así, tampoco dicha presunción es aplicable en el caso de que el préstamo sea otorgado al accionista del accionista de la persona jurídica prestamista.

Si bien la Administración Tributaria únicamente se pronunció respecto de la presunción de distribución de dividendos en el supuesto de préstamos otorgados a accionistas, fluiría del criterio establecido que el aspecto personal del impuesto a la renta a los dividendos únicamente puede comprender a los socios, asociados, titulares o integrantes de las personas jurídicas pues son quienes tienen el derecho de percibir tales utilidades. En ese sentido, los supuestos de distribución de utilidades del artículo 24-A de la Ley del Impuesto a la Renta solo pueden ser entendidos respecto de accionistas de las personas jurídicas, mas no respecto de "partes vinculadas 22 no accionistas" o "accionistas indirectos".

g) El importe de la remuneración del titular de la Empresa Individual de Responsabilidad Limitada, accionista, participacionista y en general del socio o asociado de personas

21. Hasta el 31 de diciembre de 2014, para que este tipo de crédito sea entendido a efectos del impuesto a la renta como dividendo y cualquier otra forma de distribución de utilidades era necesario que no exista una obligación de devolución del mismo o que existiendo el plazo otorgado para su devolución exceda de doce meses. Con la vigencia de la Ley 30296 a partir del 01 de enero de 2015 se suprimió dicho requisito.

22. Conforme al inciso b) del artículo 32-A de la Ley del Impuesto a la Renta, se considera que dos o más personas, empresas o entidades son partes vinculadas cuando una de ellas participa de manera directa o indirecta en la administración, control o capital de la otra; o cuando la misma persona o grupo de personas participan directa o indirectamente en la dirección, control o capital de varias personas, empresas o entidades; y también operará la vinculación cuando la transacción sea realizada utilizando personas interpuestas cuyo propósito sea encubrir una transacción entre partes vinculadas. 
jurídicas así como de su cónyuge, concubino y familiares hasta el cuarto grado de consanguinidad y segundo de afinidad, en la parte que exceda al valor de mercado.

No se consideran dividendos ni otras formas de distribución de utilidades, la capitalización de utilidades, reservas, primas, ajuste por reexpresión, excedente de revaluación o de cualquier otra cuenta de patrimonio.

Cabe señalar que el impuesto a los dividendos se paga mediante retención en la fuente, esto es, la persona jurídica domiciliada que distribuye las utilidades debe retener el $5 \%$ del monto distribuido y pagarlo al fisco dentro de los plazos establecidos para los tributos de periodicidad mensual. Si la distribución de utilidades es en especie, dicho pago debe efectuarse por la persona jurídica que las distribuya y reembolsado por el beneficiario de la distribución. Para estos efectos, el dividendo en especie se computará por el valor de mercado que corresponda atribuir a los bienes a la fecha de su distribución.

La regla referida a la retención en la fuente no resulta aplicable a las sucursales y otro tipo de establecimientos permanentes de personas jurídicas no domiciliadas en el país, ya que la legislación establece una ficción lega ${ }^{23}$ mediante la cual se entienden distribuidas las utilidades en la fecha de vencimiento del plazo para la presentación de la declaración jurada anual del Impuesto a la Renta, considerándose como monto de la distribución, la renta disponible a favor del titular del exterior. Es así que este tipo de sucursales y establecimientos permanentes tienen la obligación de pagar el 5\% del "monto distribuido" al fisco aun cuando no exista ningún acuerdo de distribución de utilidades o no se haya entregado remesas a su casa matriz.
Ahora bien, para finalizar esta sección, se debe hacer especial referencia al supuesto regulado en el inciso g) del artículo 24-A de la Ley del Impuesto a Renta que, para efectos de este impuesto, establece que se entenderá por dividendos y cualquier otra forma de distribución de utilidades a toda suma o entrega en especie que resulte renta gravable de la tercera categoría, en tanto signifique "una disposición indirecta de dicha renta no susceptible de posterior control tributario, incluyendo las sumas cargadas a gastos e ingresos no declarados".

Es así que mediante este supuesto se busca evitar que las sociedades deduzcan gastos que no corresponden para la determinación de su renta neta de tercera categoría, al estarse encubriendo la distribución indirecta de utilidades a los accionistas. Por tanto, se configura una situación de distribución de dividendos presuntos con la particularidad de que - a diferencia de los anteriores supuestos - la sociedad es el contribuyente del tributo.

Al respecto, el artículo 13-B del Reglamento de la Ley del Impuesto a la Renta dispone que los gastos que constituyen "una distribución indirecta de renta no susceptible de posterior control tributario" son aquellos susceptibles de haber beneficiado a los accionistas, participacionistas, titulares y en general a los socios o asociados de personas jurídicas, entre otros, los gastos particulares ajenos al negocio, los gastos de cargo de los accionistas, participacionistas, titulares y en general socios o asociados que son asumidos por la persona jurídica. Reuniendo la misma calificación, los siguientes gastos ${ }^{24}$ :

(i) Los gastos sustentados por comprobantes de pago falsos, constituidos por

23. Inciso e) del artículo 56 de la Ley del Impuesto a la Renta.

24. La Administración Tributaria estableció en el Informe № 025-2010-SUNAT/2B0000 que los gastos descritos en los numerales (i) al (iv) del artículo 13-B del Reglamento de la Ley del Impuesto a la Renta constituyen "disposición 
aquellos que reuniendo los requisitos y características formales señalados en el Reglamento de Comprobantes de Pago, son emitidos en alguna de las siguientes situaciones:

- El emisor no se encuentra inscrito en el Registro Único de Contribuyentes - RUC.

- El emisor se identifica consignando el número de RUC de otro contribuyente.

- Cuando en el documento, el emisor consigna un domicilio fiscal falso.

- Cuando el documento es utilizado para acreditar o respaldar una operación inexistente.

(ii) Gastos sustentados por comprobantes de pago no fidedignos, constituidos por aquellos que contienen información distinta entre el original y las copias y aquellos en los que el nombre o razón social del comprador o usuario difiera del consignado en el comprobante de pago.

(III) Gastos sustentados en comprobantes de pago emitidos por sujetos a los cuales, a la fecha de emisión de los referidos documentos, la Administración Tributaria -en adelante, "SUNAT" les ha comunicado o notificado la baja de su inscripción en el RUC o aquellos que tengan la condición de no habido, salvo que al 31 de diciembre del ejercicio, o a la fecha de cierre del balance del ejercicio, el emisor haya cumplido con levantar tal condición.

(iv) Gastos sustentados en comprobantes de pago otorgados por contribuyentes cuya inclusión en algún régimen espe- cial no los habilite para emitir ese tipo de comprobante.

(v) Gastos deducibles para la determinación del Impuesto del contribuyente domiciliado en el país, que a su vez constituyan renta de una entidad controlada no domiciliada, siempre que, ambas entidades sean partes vinculadas y dicha renta no constituya renta de fuente peruana, o esté sujeta a las presunciones de renta de fuente peruana previstas en el artículo 48 de la Ley del Impuesto a la Renta - servicios prestados parte en el país y parte en el exterior con tasa efectiva reducida-, 0 siendo íntegramente de fuente peruana esté sujeta a una tasa del Impuesto menor al $30 \%$.

(vi) Otros gastos cuya deducción sea prohibida de conformidad con la Ley, siempre que impliquen disposición de rentas no susceptibles de control tributario.

(vii) De configurarse cualquier de los casos antes descritos, la sociedad se encontrará obligada al pago —además del $29.5 \%$ del impuesto a la renta empresarial- del impuesto por concepto de "dividendos presuntos" con una tasa adicional de 5\%. Este impuesto adicional deberá abonarse al fisco dentro del mes siguiente de efectuada la disposición indirecta de la renta, en los plazos previstos para las obligaciones de periodicidad mensual. En caso no sea posible determinar el momento en que se efectuó la disposición indirecta de renta, el impuesto deberá abonarse al fisco dentro del mes siguiente a la fecha en que se devengó el gasto. De no ser posible determinar la fecha de devengo del gasto, el Impuesto se abo- 
nará en el mes de enero del ejercicio siguiente a aquel en el cual se efectuó la disposición indirecta de renta.

\section{PLANEAMIENTO FISCAL INTERNACIONAL}

A partir del ejercicio 2003, sobre la base de la Ley 27804 , se considera que los dividendos distribuidos por sociedades no domiciliadas en el país a sus accionistas domiciliados personas naturales o jurídicas - constituyen renta de fuente extranjera sujeta a imposición en nuestro país ${ }^{25}$.

Al respecto, cabe señalar que los accionistas domiciliados en el país ${ }^{26}$ deberán sumar y compensar entre sí los resultados que arrojen sus fuentes productoras de renta extranjera, y únicamente si de dichas operaciones resultase una renta neta, la misma se sumará a la renta neta de fuente peruana. En ningún caso se computará la pérdida neta total de la fuente extranjera, la que no es compensable a fin de determinar el impuesto.

Así, en caso el accionista domiciliado en el país fuese una persona jurídica generadora de rentas de tercera categoría, la distribución de dividendos se compensará con otras rentas o pérdidas de fuente extranjera, encontrándose el resultado positivo sujeto a una tasa de $29.5 \%$ en nuestro país. En caso el accionista domiciliado en el país fuese una persona natural, la renta de fuente extranjera se encontraría sujeta a una tasa de escala progresiva acumulativa $-8 \%$, $14 \%, 17 \%, 20 \%$ y $30 \%$ -
En consecuencia, mientras que la distribución de dividendos que efectúan las sociedades domiciliadas en el país a otra sociedad de igual naturaleza se encuentra exenta del impuesto a los dividendos, tratándose de una distribución de dividendos de una sociedad domiciliada en el exterior, estos deberán sumarse a la base imponible del impuesto a la renta. Lo anterior podría generar, dependiendo del sistema tributario del otro país, que esos dividendos hayan sido susceptibles de tributación en el exterior -impuesto a la renta y al distribuirse los dividendos - y a su vez, sujetos nuevamente a imposición en el país - al percibirse los dividendos del extranjero ${ }^{27}$ y al acordarse la distribución de los dividendos al accionista persona natural domiciliada.

En efecto, cuando se ven involucrados sujetos de diferentes países y, por tanto, bajo potestades tributarias distintas, el riesgo de incurrir en una doble o múltiple imposición se ve incrementado pues no todos los países contemplan los mismos supuestos de dividendos o distribución de utilidades ni los mismos criterios de vinculación para la imposición sobre los dividendos.

En la actualidad, los sistemas de tributación internacional de cada país adoptan diversas formas para aliviar o eliminar los riesgos de una doble o múltiple imposición, siendo que en el caso de Perú se adoptan específicamente métodos que parten de la legislación interna unilaterales - para abordar la situación descrita. Dichos métodos se materializan de dos maneras: (i) método de "renta mundial" o "crédito", y (ii) método "territorial" o de "exención".

25. De conformidad con el artículo 6 de la Ley del Impuesto a la Renta, las personas naturales y jurídicas domiciliadas en el país se encuentran sujetas al impuesto a la renta tanto por sus rentas de fuente peruana como de fuente extranjera - renta de fuente mundial一.

26. El accionista domiciliado no se encontrará sujeto a la retención del $5 \%$ ya que quien reparte los dividendos es un sujeto no domiciliado que no se encuentra bajo los alcances de las disposiciones aplicables a los agentes de retención de la Ley del Impuesto a la Renta.

27. De acuerdo al inciso d) del artículo 57 de la Ley del Impuesto a la Renta, para que la afectación de dicha renta tenga lugar en el Perú, resultará necesario que desde el exterior se tome el acuerdo de distribución de dividendos a favor del accionista domiciliado en el país ya que la renta de fuente extranjera se grava en el período en que se perciba, salvo que provenga de la explotación de un negocio o una empresa en el exterior en cuyo caso rige el principio del devengado. 
Mediante el primer método, los riesgos de una doble o múltiple imposición son reducidos por la Ley del Impuesto a la Renta a través de un mecanismo de crédito tributario por los impuestos a la renta abonados en el exterior. No obstante, la posibilidad de reducir la carga tributaria se encuentra sujeta a límites, así el inciso e) del artículo 88 de la Ley del Impuesto a la Renta establece que los contribuyentes podrán deducir de su impuesto aquellos impuestos a la renta abonados en el exterior por rentas de fuente extranjera gravadas por esta Ley, siempre que no excedan del importe que resulte de aplicar la tasa media del contribuyente a las rentas obtenidas en el extranjero, ni el impuesto efectivamente pagado en el exterior ${ }^{28}$. El importe que, por cualquier circunstancia, no se utilice en el ejercicio gravable, no podrá compensarse en otros ejercicios ni dará derecho a devolución alguna.

Como puede observarse, el mecanismo de crédito tributario resulta siendo insuficiente para cubrir los riesgos de una doble o múltiple imposición por las limitaciones a los cuales se encuentra sujeto, ya que dependiendo de las legislaciones tributarias extranjeras, podría nunca llegarse a absorber el importe total del impuesto pagado en el exterior que haya gravado las mismas rentas.

Sin perjuicio de lo anterior, bajo el segundo método, se emplean los Convenios para Evitar la Doble Imposición como mecanismos para mitigar la doble o múltiple imposición tributaria al tratarse de acuerdos entre Estados que se basan en la distribución de poder tributario, lo que se traduce en una cesión de soberanía fiscal entre los respectivos Estados. Es así que se termina gravando en el Estado de la fuente determinadas rentas y en el Estado de residencia otras.

A continuación, se efectúa una breve descripción de los Convenios que a la fecha se encuentran vigentes y plenamente aplicables en el Perú, en la parte correspondiente al tratamiento de los dividendos.

\section{Convenio suscrito con Chile.}

Este Convenio fue aprobado mediante Resolución Legislativa № 27905 publicada con fecha 06 de enero de 2003 y ratificado mediante Decreto Supremo No 005-2003-RE publicado con fecha 17 de enero de 2003, siendo plenamente aplicable desde el primero de enero de 2004.

En lo concerniente al tratamiento de los dividendos, el Artículo 10 del Convenio establece una jurisdicción compartida al señalar que los dividendos pagados por una sociedad residente de un Estado contratante -Perú- a un residente de otro Estado contratante -Chile- pueden someterse a imposición en ese otro Estado Chile-. Es decir, los dividendos pagados por una sociedad peruana a una sociedad chilena pueden someterse a imposición en Chile.

El citado Artículo agrega que dichos dividendos pueden también someterse a imposición en el Estado contratante en que resida la sociedad que pague los dividendos - Perú- y según la legislación de este Estado -Perú-, es decir, dichos dividendos también pueden someterse a imposición en el Perú bajo su régimen impositivo. Sin embargo, en este supuesto el impuesto exigido al beneficiario de los dividendos del otro Estado contratante — sociedad chilena- estará sujeto a las siguientes tasas máximas:

a) $10 \%$ del importe bruto de los dividendos, si el beneficiario efectivo es una sociedad que controla directa o indirectamente no menos del $25 \%$ de las acciones con derecho a voto de la sociedad que paga dichos dividendos; $y$

b) $15 \%$ del importe bruto de los dividendos en todos los demás casos.

Asimismo, se establece en el Apartado 2 del Protocolo que las tasas máximas previstas para los dividendos no limitarán la aplicación del

28. El artículo 52 del Reglamento de la Ley del Impuesto a la Renta precisa que la tasa media es el porcentaje que resulte de relacionar el impuesto determinado con la renta neta global o con la renta de tercera categoría, según fuera el caso. 
Impuesto Adicional a pagar en Chile en la medida de que el Impuesto de Primera Categoría — renta empresarial - sea deducible contra el Impuesto Adicional. La misma regla se aplicará a Perú en el supuesto de que en el futuro se establezca un régimen tributario integrado similar al que rige en Chile a la firma del Convenio, el que deberá incluir un crédito total o con efecto equivalente por el Impuesto a la Renta, contra el impuesto de retención que afecta la distribución o remesa de utilidades.

\section{Convenio suscrito con Canadá.}

Este Convenio fue aprobado mediante Resolución Legislativa № 27904 publicada con fecha 05 de enero de 2003 y ratificado mediante Decreto Supremo No 022-2003-RE publicado con fecha 05 de febrero de 2003, siendo plenamente aplicable desde el primero de enero de 2004.

En lo concerniente al tratamiento de los dividendos, el Artículo 10 del Convenio establece una jurisdicción compartida al señalar que los dividendos pagados por una sociedad residente de un Estado contratante - Perú - a un residente de otro Estado contratante - Canadá- pueden someterse a imposición en ese otro Estado Canadá-. Es decir, los dividendos pagados por una sociedad peruana a una sociedad canadiense pueden someterse a imposición en Canadá.

El citado Artículo agrega que dichos dividendos pueden también someterse a imposición en el Estado contratante en que resida la sociedad que pague los dividendos - Perú- y según la legislación de este Estado -Perú-, es decir, dichos dividendos también pueden someterse a imposición en el Perú bajo su régimen impositivo. Sin embargo, en este supuesto el impuesto exigido al beneficiario de los dividendos del otro Estado contratante - sociedad canadienseestará sujeto a las siguientes tasas máximas:

a) $10 \%$ del importe bruto de los dividendos, si el beneficiario efectivo es una sociedad que controla directa o indirectamente no menos del $10 \%$ de las acciones con derecho a voto de la sociedad que paga dichos dividendos; $y$ b) $15 \%$ del importe bruto de los dividendos en todos los demás casos.

Por último, el literal a) Apartado 3 del Protocolo dispone que si en virtud de un acuerdo o convenio celebrado con un país miembro de la $O C D E$, en una fecha posterior a la que se firma el Convenio, Perú acuerda una tasa de impuesto sobre dividendos que sea menor al $10 \%$ se aplicará automáticamente la mayor entre dicha nueva tasa y una tasa del $5 \%$.

Nótese que la mencionada disposición del Protocolo constituye una "Cláusula de Nación Más Favorecida", tema al que la doctrina comparada ha venido prestando atención al observarse una tendencia en los últimos años de incluir este tipo de cláusulas en los Convenios para Evitar la Doble Imposición debido a que si bien estas cláusulas son comunes en los acuerdos vinculados al comercio internacional, su inclusión en estos Convenios debe ser limitada y excepcional.

Mediante la "Cláusula de Nación Más Favorecida", un Estado se obliga frente a otro Estado a no tratarlo de manera menos favorable que a un tercer Estado. En ese sentido, es usual que se confunda esta Cláusula con aquella referida al principio de no discriminación bajo comentario en el primer apartado del presente documento.

Aun cuando los Convenios para Evitar la Doble Imposición suelen incorporar Cláusulas de No Discriminación per se, esta no es una obligación de Nación Más Favorecida que permita extender el tratamiento fiscal más favorable acordado en el marco de dicho Convenio entre dos Estados contratantes a los nacionales o residentes de terceros Estados. Más aún, la "Cláusula de Nación Más Favorecida" resulta incompatible con la naturaleza bilateral y el principio de reciprocidad consustancial a los Convenios para Evitar la Doble Imposición.

A pesar de lo mencionado, tanto el Protocolo del Convenio para Evitar la Doble Imposición suscrito con Canadá como otros que veremos más adelante contemplan una "Cláusula de $\mathrm{Na}$ ción Más Favorecida" para rentas pasivas como los dividendos. No obstante, hasta el momento no se cuenta en el país con un pronunciamiento

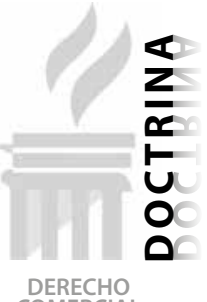


por parte de Administración Tributaria sobre el particular, dicha posición oficial en relación con la aplicación de la "Cláusula de Nación Más Favorecida" en los Convenios para Evitar la Doble Imposición suscritos por Perú resulta indispensable en aras de la seguridad jurídica ${ }^{29}$.

\section{Convenio suscrito con la Comunidad Andina.}

Con fecha 04 de mayo de 2004 se adoptó la Decisión 578 denominada Régimen para Evitar la Doble Imposición y Prevenir la Evasión Fiscal, el mismo que comprende los países miembros del Pacto Andino - Acuerdo de Cartagena- ${ }^{30}$. La Decisión 578 es plenamente aplicable desde el primero de enero de 2005.

En lo concerniente al tratamiento de los dividendos, el artículo 11 de la Decisión 578 dispone que los mismos serán gravados en el país donde domicilia la empresa que los distribuye. El país donde se domicilie la empresa o persona beneficiaria de los dividendos no podrá gravarlo en cabeza de la sociedad receptora o inversionista, ni tampoco en cabeza de quienes a su vez sean accionistas o socios de la empresa receptora o inversionista. No se establecen tasas máximas de imposición a los dividendos.

\section{Convenio suscrito con Brasil.}

Este Convenio fue aprobado mediante Resolución Legislativa № 29233 publicada con fecha 22 de mayo de 2008 y ratificado mediante Decreto Supremo No 019-2008-RE publicado con fecha 06 de junio de 2008, siendo plenamente aplicable desde el primero de enero de 2010.

En lo concerniente al tratamiento de los dividendos, el Artículo 10 del Convenio establece una jurisdicción compartida al señalar que los dividendos pagados por una sociedad residente de un Estado contratante -Perú- a un residente de otro Estado contratante - Brasil- pueden someterse a imposición en ese otro Estado Brasil-. Es decir, los dividendos pagados por una sociedad peruana a una sociedad brasilera pueden someterse a imposición en Brasil.

El citado artículo agrega que dichos dividendos pueden también someterse a imposición en el Estado contratante en que resida la sociedad que pague los dividendos -Perú- y según la legislación de este Estado —Perú-, es decir, dichos dividendos también pueden someterse a imposición en el Perú bajo su régimen impositivo. Sin embargo, en este supuesto el impuesto exigido al beneficiario de los dividendos del otro Estado contratante - sociedad brasilera- estará sujeto a las siguientes tasas máximas:

a) $10 \%$ del importe bruto de los dividendos, si el beneficiario efectivo es una sociedad que controla directa o indirectamente no menos del $20 \%$ de las acciones con derecho a voto de la sociedad que paga dichos dividendos; $y$

b) $15 \%$ del importe bruto de los dividendos en todos los demás casos.

\section{Convenio suscrito con México.}

Este Convenio fue aprobado mediante Resolución Legislativa № 30144 publicada con fecha 28 de diciembre de 2013 y ratificado mediante Decreto Supremo No 003-2014-RE publicado con fecha 16 de enero de 2014, siendo plenamente aplicable desde el primero de enero de 2015.

En lo concerniente al tratamiento de los dividendos, el artículo 10 del Convenio establece una jurisdicción compartida al señalar que los dividendos pagados por una sociedad residente de un Estado contratante -Perú- a un residente de otro Estado contratante - México- pueden someterse a imposición en ese otro Estado -

29. En otras jurisdicciones, la aplicación de la "Cláusula de Nación Más Favorecida" se dirime mediante un pronunciamiento oficial emitido por la Autoridad Tributaria correspondiente, el cual tiene carácter vinculante y es puesto en conocimiento de la Autoridad Tributaria del Estado contraparte.

30. Los países miembros del Pacto Andino son Ecuador, Bolivia, Colombia y Perú. 
México-. Es decir, los dividendos pagados por una sociedad peruana a una sociedad mexicana pueden someterse a imposición en México.

El citado Artículo agrega que dichos dividendos pueden también someterse a imposición en el Estado contratante en que resida la sociedad que pague los dividendos -Perú- y según la legislación de este Estado —Perú-, es decir, dichos dividendos también pueden someterse a imposición en el Perú bajo su régimen impositivo. Sin embargo, en este supuesto el impuesto exigido al beneficiario de los dividendos del otro Estado contratante - sociedad mexicana- estará sujeto a las siguientes tasas máximas:

a) $10 \%$ del importe bruto de los dividendos, si el beneficiario efectivo es una sociedad que controla directa o indirectamente no menos del $25 \%$ de las acciones con derecho a voto de la sociedad que paga dichos dividendos; $y$

b) $15 \%$ del importe bruto de los dividendos en todos los demás casos.

Por último, el Apartado 4 del Protocolo dispone que, si en virtud de un acuerdo o convenio celebrado entre Perú y un tercer Estado que entre en vigencia en una fecha posterior a la fecha de entrada en vigencia del presente Convenio, se limite el gravamen a los dividendos a una tasa menor que aquella prevista en el artículo 10, la tasa inferior deberá aplicarse automáticamente sobre los dividendos procedentes del Perú, y cuyo beneficiario efectivo sea un residente de México, y sobre los dividendos procedentes de México y cuyo beneficiario efectivo sea un residente de Perú, bajo las mismas condiciones como si tal tasa inferior hubiera sido especificada en el Artículo 10. La autoridad competente del Perú deberá informar a la autoridad competente de México, sin retraso, que se han reunido las condiciones para la aplicación del Apartado 4.

Nótese que la mencionada disposición del Protocolo constituye una "Cláusula de Nación Más Favorecida" similar a la que se encuentra en el Convenio para Evitar la Doble Imposición suscrito con Canadá, razón por la cual, le son aplicables los mismos comentarios.

\section{Convenio suscrito con Corea del Sur.}

Este Convenio fue aprobado mediante Resolución Legislativa № 30140 publicada con fecha 27 de diciembre de 2013 y ratificado mediante Decreto Supremo No 004-2014-RE publicado con fecha 26 de febrero de 2014, siendo plenamente aplicable desde el primero de enero de 2015.

En lo concerniente al tratamiento de los dividendos, el artículo 10 del Convenio establece una jurisdicción compartida al señalar que los dividendos pagados por una sociedad residente de un Estado contratante -Perú- a un residente de otro Estado contratante - Corea del Sur - pueden someterse a imposición en ese otro Estado - Corea del Sur-. Es decir, los dividendos pagados por una sociedad peruana a una sociedad surcoreana pueden someterse a imposición en Corea del Sur.

El citado Artículo agrega que dichos dividendos pueden también someterse a imposición en el Estado contratante en que resida la sociedad que pague los dividendos - Perú- y según la legislación de este Estado -Perú-, es decir, dichos dividendos también pueden someterse a imposición en el Perú bajo su régimen impositivo. Sin embargo, en este supuesto el impuesto exigido al beneficiario de los dividendos del otro Estado contratante - sociedad surcoreanaestará sujeto a una tasa máxima de $10 \%$ del importe bruto de los dividendos.

De otro lado, el Apartado 3 del Protocolo dispone que, si en virtud de un acuerdo o convenio celebrado entre Perú y un tercer Estado, Perú acuerda limitar la tasa sobre el impuesto a los dividendos a tasas más bajas que las previstas en este Convenio, esta tasa reducida se aplicará automáticamente a tales dividendos bajo este Convenio como si esta tasa reducida hubiera sido especificada en el mismo desde la fecha en que las disposiciones de ese acuerdo o convenio sean aplicables. La autoridad competente del Perú informará sin demora a la autoridad competente de Corea del Sur que se ha cumplido las condiciones para la aplicación del Apartado 3.

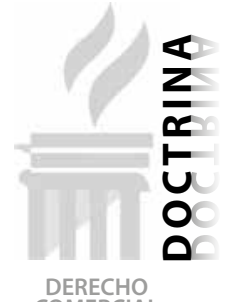


Nótese que la mencionada disposición del Protocolo constituye una "Cláusula de Nación Más Favorecida" similar a la que se encuentra en el Convenio para Evitar la Doble Imposición suscrito con Canadá y México, razón por la cual, le son aplicables los mismos comentarios.

\section{Convenio suscrito con Suiza.}

Este Convenio fue aprobado mediante Resolución Legislativa № 30143 publicada con fecha 28 de diciembre de 2013 y ratificado mediante Decreto Supremo No 008-2014-RE publicado con fecha 28 de febrero de 2014, siendo plenamente aplicable desde el primero de enero de 2015.

En lo concerniente al tratamiento de los dividendos, el Artículo 10 del Convenio establece una jurisdicción compartida al señalar que los dividendos pagados por una sociedad residente de un Estado contratante - Perú- a un residente de otro Estado contratante - Suiza - pueden someterse a imposición en ese otro Estado Suiza-. Es decir, los dividendos pagados por una sociedad peruana a una sociedad suiza pueden someterse a imposición en Suiza.

El citado Artículo agrega que dichos dividendos pueden también someterse a imposición en el Estado contratante en que resida la sociedad que pague los dividendos - Perú- y según la legislación de este Estado —Perú-, es decir, dichos dividendos también pueden someterse a imposición en el Perú bajo su régimen impositivo. Sin embargo, en este supuesto el impuesto exigido al beneficiario de los dividendos del otro Estado contratante — sociedad suiza- estará sujeto a las siguientes tasas máximas:

a) $10 \%$ del importe bruto de los dividendos, si el beneficiario efectivo es una sociedad que posea al menos directamente al menos 10\% del capital y de las acciones con derecho a voto de la sociedad que paga los dividendos; $y$

b) $15 \%$ del importe bruto de los dividendos en todos los demás casos.

Por último, el Apartado 10 del Protocolo dispone que, si en virtud de un acuerdo o convenio cele- brado entre Perú y un tercer Estado, Perú acuerda eximir de impuestos a los dividendos provenientes de Perú o limitar la tasa del impuesto sobre los dividendos a tasa más bajas que las previstas en el Convenio, esa exención o tasa reducida se aplicará automáticamente a este Convenio como si la exención o tasa reducida hubiera sido especificada en el mismo desde la fecha en que las disposiciones de ese acuerdo o convenio sean aplicables. La autoridad competente del Perú informará sin demora a la autoridad competente de Suiza que se han cumplido las condiciones para la aplicación del Apartado 10.

Nótese que la mencionada disposición del Protocolo constituye una "Cláusula de Nación Más Favorecida" similar a la que se encuentra en el Convenio para Evitar la Doble Imposición suscrito con Canadá, México y Corea del Sur, razón por la cual, le son aplicables los mismos comentarios.

\section{Convenio suscrito con Portugal.}

Este Convenio fue aprobado mediante Resolución Legislativa № 30141 publicada con fecha 27 de diciembre de 2013 y ratificado mediante Decreto Supremo No 009-2014-RE publicado con fecha 06 de marzo de 2014, siendo plenamente aplicable desde el primero de enero de 2015.

En lo concerniente al tratamiento de los dividendos, el Artículo 10 del Convenio establece una jurisdicción compartida al señalar que los dividendos pagados por una sociedad residente de un Estado contratante -Perú- a un residente de otro Estado contratante -Portugal- pueden someterse a imposición en ese otro Estado - Portugal-. Es decir, los dividendos pagados por una sociedad peruana a una sociedad portuguesa pueden someterse a imposición en Portugal.

El citado Artículo agrega que dichos dividendos pueden también someterse a imposición en el Estado contratante en que resida la sociedad que pague los dividendos —Perú- y según la legislación de este Estado -Perú-, es decir, dichos dividendos también pueden someterse a imposición en el Perú bajo su régimen impositivo. Sin embargo, en este supuesto el impuesto 
exigido al beneficiario de los dividendos del otro Estado contratante - sociedad portuguesaestará sujeto a las siguientes tasas máximas:

a) $10 \%$ del importe bruto de los dividendos, si el beneficiario efectivo es una sociedad que: (i) posea directamente al menos $10 \%$ del capital de la sociedad que paga los dividendos, si tal sociedad es residente de Portugal; o (ii) controle directamente al menos $10 \%$ de las acciones con derecho a voto de la sociedad que paga los dividendos, si tal sociedad es residente de Perú; $y$

b) $15 \%$ del importe bruto de los dividendos en todos los demás casos.

Tasas máximas aplicables al importe bruto de los dividendos bajo los Convenios de Doble Imposición Tributaria suscritos por el Perú

\begin{tabular}{|c|c|c|}
\hline $\begin{array}{l}\text { País con el cual } \\
\text { el Perú suscribió } \\
\text { un Convenio para } \\
\text { Evitar la Doble } \\
\text { Imposición }\end{array}$ & $\begin{array}{c}\text { Fecha de } \\
\text { aplicación del } \\
\text { Convenio para } \\
\text { Evitar la Doble } \\
\text { Imposición }\end{array}$ & $\begin{array}{c}\text { Tasa máxima } \\
\text { del impuesto } \\
\text { a la renta a } \\
\text { los dividen- } \\
\text { dos }\end{array}$ \\
\hline Chile & $\begin{array}{c}01 \text { de enero de } \\
2004\end{array}$ & $10 \% / 15 \%$ \\
\hline Canadá & $\begin{array}{c}01 \text { de enero de } \\
2004\end{array}$ & $10 \% / 15 \%$ \\
\hline $\begin{array}{c}\text { Comunidad Andina } \\
\text { (Colombia, Ecuador } \\
\text { y Bolivia) }\end{array}$ & $\begin{array}{l}01 \text { de enero de } \\
2005\end{array}$ & - \\
\hline Brasil & $\begin{array}{c}01 \text { de enero de } \\
2010\end{array}$ & $10 \% / 15 \%$ \\
\hline México & $\begin{array}{c}01 \text { de enero de } \\
2015\end{array}$ & $10 \% / 15 \%$ \\
\hline Corea del Sur & $\begin{array}{c}01 \text { de enero de } \\
2015\end{array}$ & $10 \%$ \\
\hline Suiza & $\begin{array}{c}01 \text { de enero de } \\
2015\end{array}$ & $10 \% / 15 \%$ \\
\hline Portugal & $\begin{array}{c}01 \text { de enero de } \\
2015\end{array}$ & $10 \% / 15 \%$ \\
\hline
\end{tabular}

\section{CONCLUSIONES}

a) En el Perú se garantiza un tratamiento fiscal igualitario a los inversionistas extranjeros y nacionales, lo cual no enerva que en atención a la particular situación fiscal de los inversionistas extranjeros se introduzca consideraciones fiscales diferenciadas respecto a los mismos, siempre que, como resultado final la carga fiscal que soporta el inversio- nista extranjero le permita competir bajo las mismas condiciones con los inversionistas nacionales. Dichas consideraciones fiscales diferenciadas deben ser introducidas en razón a la capacidad contributiva del inversionista extranjero, resultando irrelevante cualquier consideración subjetiva - origen del capital, tipo de personería jurídica, domicilio del inversionista, etc.-.

b) Entre 1982 a 1993, el método de gravabilidad por el cual optó el legislador en materia fiscal fue el de la "teoría del ente separado o doble imposición sociedad-socio", por medio del cual, las rentas empresariales se encontraban afectas al impuesto a la renta a nivel de las sociedades que lo generaban, y a nivel de los accionistas cuando las utilidades eran distribuidas. Paralelamente, se adoptó también la "teoría de integración impositiva" al vincular el impuesto a la renta de la sociedad con el correspondiente al accionista, mediante el otorgamiento de créditos a las personas naturales beneficiarias de los dividendos distribuidos por las sociedades para ser aplicado contra el impuesto a la renta a su cargo.

c) Entre 1994 a 2002 se modificó sustancialmente el régimen del impuesto a la renta, pues las rentas empresariales se encontraban gravadas únicamente a nivel de las sociedades que las generaban, mas no a nivel de los accionistas. Asimismo, a fin de incentivar la reinversión de utilidades de las sociedades domiciliadas en el país se dispuso que, si las mismas distribuían total o parcialmente utilidades, debían de aplicar una tasa adicional de $4.1 \%$ sobre el monto distribuido, salvo que la distribución sea efectuada a favor de otra sociedad domiciliada.

d) A partir del 2003, los dividendos distribuidos vuelven a encontrarse gravados en cabeza de los accionistas beneficiados, con lo cual las rentas empresariales nuevamente se encuentran gravadas a dos niveles. Sin embargo, se establece una imposición de tipo cedular sobre dichas rentas evitando que se integre a la renta neta global de las

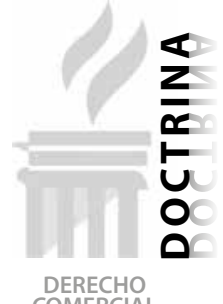


personas naturales, es decir, las mismas no son susceptibles de ser integradas a las demás rentas de los accionistas y tampoco genera el derecho de crédito alguno.

e) Las últimas modificaciones tributarias se han concentrado en una reforma combinada de las tasas impositivas del impuesto a la renta empresarial de los contribuyentes domiciliados y de los dividendos y cualquier otra forma de distribución de utilidades de fuente peruana, con el objetivo de reactivar la economía del país mediante una mayor recaudación tributaria.

f) A pesar de las reformas introducidas, no se logró acelerar las inversiones en el país durante el 2015 y 2016, es decir, no se promovió la reinversión de utilidades de las empresas y no se atrajo inversión extranjera, dado que, desde el año 2012, se experimentó una reducción en la tasa de crecimiento de la inversión bruta fija privada, siendo que en el año 2014 dicha tasa fue negativa e igual a $2.3 \%$.

g) A partir del 01 de enero de 2017, con el objetivo de solucionar la problemática expuesta, se redujo la tasa impositiva aplicable a los dividendos y otras formas de distribución de utilidades a cargo de personas naturales domiciliadas o no en el país y de personas jurídicas no domiciliadas, de $6.8 \%$ a $5 \%$. Siendo que, en paralelo, a fin de garantizar que la carga tributaria se mantenga, se incrementó de $28 \%$ a $29.5 \%$ la tasa del impuesto a la renta empresarial de las personas jurídicas domiciliadas.

h) La tasa impositiva sobre los dividendos no es una tasa adicional a cargo de las sociedades que efectúan su distribución sino que se trata de una tasa correspondiente a un tributo en cabeza de los accionistas beneficiarios, razón por la cual, el impuesto sobre los dividendos es pagado mediante retención en la fuente, esto es, la persona jurídica domiciliada que distribuye las utilidades deberá retener el $5 \%$ del monto distribuido y pagarlo al fisco dentro de los plazos establecidos para los tributos de periodicidad mensual. En caso el perceptor del dividendo sea una persona jurídica domiciliada a esta no se le retendrá.

i) La regla referida a la retención en la fuente no resulta aplicable a las sucursales y otro tipo de establecimientos permanentes de personas jurídicas no domiciliadas en el país ya que la legislación peruana establece una ficción legal mediante la cual se entienden distribuidas las utilidades en la fecha de vencimiento del plazo para la presentación de la declaración jurada anual del Impuesto a la renta, considerándose como monto de la distribución, la renta disponible a favor del titular del exterior.

j) El artículo 24-A de la Ley del Impuesto a la Renta no se limita a una definición societaria sobre los "dividendos" referida a las utilidades en efectivo o en especie distribuidas por personas jurídicas domiciliadas a las personas que la integran al cierre de un período sino que en virtud de la autonomía del Derecho Tributario se han considerado supuestos adicionales para fines impositivos, tales como, la capitalización de utilidades, reservas, primas, ajuste por reexpresión, excedente de revaluación o de cualquier otra cuenta de patrimonio.

k) Un supuesto especial es el regulado en el inciso g) del artículo 24-A de la Ley del Impuesto a la Renta, que para efectos de este impuesto, establece que se entenderá por dividendos y cualquier otra forma de distribución de utilidades a toda suma o entrega en especie que resulte renta gravable de la tercera categoría, en tanto signifique "una disposición indirecta de dicha renta no susceptible de posterior control tributario, incluyendo las sumas cargadas a gastos e ingresos no declarados". De configurarse un caso de disposición indirecta de renta, la sociedad se encontrará obligada al pago del impuesto en calidad de contribuyente por concepto de "dividendo presunto" con una tasa adicional del 5\%, además del $29.5 \%$ del impuesto a la renta empresarial que se encuentra obligada a pagar. 
I) En el Perú se han adoptado métodos unilaterales - legislación interna- para aliviar o eliminar los riesgos de una doble o múltiple imposición, siendo los mismos de dos tipos: (i) método de "renta mundial" o "crédito" referido al crédito otorgado por los impuestos a la renta abonados en el exterior, y (ii) método "territorial" o de "exención" referido a los Convenios para Evitar la Doble Imposición suscritos entre el Perú y países como Chile, Canadá, miembros de la Comunidad Andina - Colombia, Bolivia y Ecuador-, Brasil, México, Corea del Sur, Suiza y Portugal.

m) En los Convenios para Evitar la Doble Imposición suscritos por el Perú, se ha establecido la tributación compartida de los dividendos y tasas máximas aplicables al importe bruto de los dividendos, que varían entre $10 \%$ y $15 \%$, salvo en el caso del Convenio con Corea del Sur en el cual se fija $10 \%$ como tasa máxima.

n) En el caso de los Convenios para Evitar la Doble Imposición suscritos entre el Perú y Canadá, México, Corea del Sur y Suiza, se ha establecido una "Cláusula de Nación Más Favorecida" respecto a los dividendos que no es común en este tipo de acuerdos bilaterales. No obstante, hasta el momento el Perú no cuenta con un pronunciamiento por parte de la Administración Tributaria sobre el particular, dicha posición oficial en relación con la aplicación de la "Cláusula de Nación Más Favorecida" en los Convenios para Evitar la Doble Imposición suscritos por el Perú resulta indispensable en aras de la seguridad jurídica. 